\title{
The $p 53$ codon 72 polymorphism and association to prostate cancer in Iranian patients
}

\author{
Abbas Doosti ${ }^{1 \star}$ and Payam Ghasemi Dehkordi ${ }^{1,2}$ \\ ${ }^{1}$ Biotechnology Research Center, Islamic Azad University, Shahrekord Branch, Shahrekord, Iran. \\ ${ }^{2}$ Islamic Azad University, Shahrekord Branch, Young Researchers Club, Shahrekord, Iran. \\ Accepted 1 September, 2011
}

\begin{abstract}
Tp53 is an important tumor suppressor gene, which induces cell growth arrest or apoptosis when subjected to cytotoxic stimuli. Association has been reported between various cancers and p53 codon 72 polymorphism. Our objective was to investigate the possible association between $p 53$ at codon 72 for Arg/Arg, Arg/Pro and Pro/Pro allele polymorphisms in blood samples from 187 prostate cancer patients and 185 controls in southwest Iran by nested-polymerase chain reaction (PCR) of p53 exon 4 and digestion with BstU restriction enzyme and the DNA fragments were then resolved by electrophoresis in 2\% agarose gel. The frequencies of Arg/Arg, Arg/Pro and Pro/Pro genotypes were $39.57 \%(74 / 187), 52.41 \%(98 / 187)$ and $8.02 \%(15 / 187)$, respectively, in the cases with prostate cancer, and $27.03 \%(50 / 185), 60 \%(111 / 185)$ and $12.97 \%(24 / 185)$, respectively in the healthy controls. Statistically, analyzed and combined results showed there was a significant difference in the frequency of the Arg/Arg genotype and Arg allele between prostate cancer cases and control ( $p>0.001)$. These findings suggest that $p 53 \mathrm{Arg} / \mathrm{Arg}$ genotype could be a risk factor for the development of prostate cancer among patients in southwest Iran.
\end{abstract}

Key words: Prostate cancer, suppressor gene (p53) codon 72, polymorphism, Iran.

\section{INTRODUCTION}

The prostate gland is a male sex gland. Located below the urinary bladder, it is about the size of a walnut. The urethra, a tube that transports urine, passes through the prostate (Huang et al., 2004). Prostate cancer occurs when cells in the prostate gland grow out of control. Prostate cancer is the fifth most common cancer in the world and the second most common cancer among men (Zhu et al., 2010). There are often no early prostate cancer symptoms, but some men have urinary symptoms and discomfort. Some prostate cancers do not stay in the prostate, but spread to other parts of the body such as the bones and lymph nodes. This is called metastatic prostate cancer. Many studies indicate that environmental and genetic factors such as p53 gene play a

*Corresponding author. E-mail: biologyshk@yahoo.com. Tel: +98-3813-361001. Fax: +98-3813-361001.

Abbreviations: Tp53, Tumor suppressor gene p53; RFLP, restriction fragment length polymorphism. significant role in the etiology of this disease (Quinones et al., 2006). Given the multicausal etiology of prostate cancer, synergistic interactions among genetic and other risk factors might have significant effects on prostate cancer risk, especially gene-gene $(G \times G)$ and geneenvironment $(\mathrm{G} \times \mathrm{E})$ interactions (Quinones et al., 2006 However, for men who have a father or brother with prostate cancer, their risk is known to be higher. The risk is higher again if more than one member of your family has prostate cancer.

This cancer accounting for almost $11.7 \%$ of new cancer cases overall, constitutes 19\% of cancers in developed countries and 5.3\% in developing countries (Sadjadi et al., 2007).

Prostate cancer also accounts for $33 \%$ of all newly diagnosed malignancies among men in the United States. According to the American Cancer Society, an estimated 220,900 men will be diagnosed with prostate cancer in 2003, and 28,900 men will die of it, making it the second most common cause of cancer death in men. In 2007, the estimated number of new cases affected by prostate cancer was 782600 with 254000 deaths (Guan 
et al., 2006). More than 11,000 men are diagnosed with it and 2700 die of it in Australia each year. Prostate cancer is very age dependent, so that more than half of all new prostate cancers and over $80 \%$ of prostate cancer deaths occur in men over the age of 70 (Pietsch et al., 2006).

p53 is the most commonly mutated gene in human cancers and more than $50 \%$ of human tumors contain inactivating mutations of p53 gene (Guan et al., 2006). The human $p 53$ tumor suppressor gene is located on chromosome $17 \mathrm{p} 13$ and encodes a $53-\mathrm{kDa}$ nuclear phosphoprotein, which plays a central role in many cellular processes such as cell-cycle control, DNA repair and apoptosis in prostate cancer. Mutations of this gene are frequently seen in both germ line and somatic forms (Zhu et al., 2010; Huang et al., 2004). The p53 protein is activated in response to various genotoxic and nongenotoxic stimulus, triggering the expression of several genes that affect DNA repair (via the GADD45 pathway) and cell cycle arrest (via the p21 pathway). If repair fails, apoptosis is triggered (via the bax pathway), hence, the denomination of p53 as the "genome guardian" (LimaRamos et al., 2008; Vazquez et al., 2010).

The codon 72 polymorphism is located in exon 4 of the p53 gene, a region involving very few mutations. p53 protein exhibits a common polymorphism at amino acid 72, resulting in either a proline residue (CCC) or an arginine residue (CGC) (Guan et al., 2006; Cao et al., 2009). Three genotypes occur: arginine homozygotes (Arg/Arg), proline homozygotes (Pro/Pro), and heterozygotes (Pro/Arg). A guanine/cytosine variant at the second position of codon 72 on exon 4 leads to Arg72 or Pro72 protein variants with markedly altered primary structures and different biochemical functions. The current view is that the P53-Arg72 protein is more effective than the P53-Pro72 protein at inducing apoptosis and protecting cells from tumor development (Li et al., 2010; Huang et al., 2004).

Most studies investigating potential risk factors for prostate cancer have been conducted in the West, with consistent demographic findings including older age, family history, African American race, and residence in a Western nation (Hosseini et al., 2009). The incidence of prostate cancer is much lower in Asian than Western populations and the disease and its risk factors have been less studied in the region, including Iran (Pourmand et al., 2007; Hosseini et al., 2009) .In the present study, we examined the genotype frequency of codon 72 in prostate cancer patients and determined the role of the p53 polymorphism in Southwest Iran using Nestedpolymerase chain reaction (PCR) and restriction fragment length polymorphism (RFLP) analysis with BstUl restriction enzyme.

\section{MATERIALS AND METHODS}

\section{Patient and control populations}

We conducted a case-control study on risk factors for prostate cancer between 2009 and 2010 in the Chaharmahal Va Bakhtiari province located in Southwest Iran. A total of 187 male prostate cancer cases with ethical symptoms such as sudden need to urinate often at night; painful urination, etc., (median age: 61.46, range: 45 and 88 years) arose during the study period. Blood samples of 185 people (median age: 58.12, range: 43 and 87 years) selected randomly from among clinical laboratories and were negative for cancer were used as controls.

\section{DNA preparation}

Total DNA was extracted from the blood samples using a DNA extraction kit (QIAGEN Ltd., Crawley, UK) according to the manufacturer's procedure. The extracted DNA was stored at $-20^{\circ} \mathrm{C}$ until needed for amplification.

\section{TP53 Arg72Pro genotyping analysis and gene amplification}

Analysis of TP53 Arg72Pro polymorphism was performed by Nested-PCR and PCR-RFLP. The primers used for one-step amplification were D1-F: 5'-GCT CTT TTC ACC CAT CTA CAG- 3' and D2-R: 5'-TGA AGT CTC ATG GAA GCC AGC- 3', while those used for two-step amplification were F2-F: 5'-TCC CCC TTG CCG TCC CAA- 3' and R2-R: 5'-CGT GCA AGT CAC AGA CTT- 3'. Briefly, amplification reaction was carried out in a total volume of 25 $\mu \mathrm{L}$, consisting of $1 \mu \mathrm{g}$ of template DNA, $1 \mu \mathrm{M}$ of each primers, 2 $\mathrm{mM} \mathrm{Mgcl}_{2}, 200 \mu \mathrm{M}$ dNTP, $5 \mu \mathrm{L}$ of $10 \times$ PCR buffer and $1 \mathrm{U}$ of Taq DNA polymerase (Roche applied science). PCR amplification was performed in a Mastercycler Gradiant (Eppendorf, Germany) with an initial denaturation step at $95^{\circ} \mathrm{C}$ for $5 \mathrm{~min}$, then amplified for 30 cycles of denaturation at $94^{\circ} \mathrm{C}$ for $1 \mathrm{~min}$, annealing at $58^{\circ} \mathrm{C}$ for 1 min, extension at $72^{\circ} \mathrm{C} 1 \mathrm{~min}$ and, final extension step at $72{ }^{\circ} \mathrm{C}$ for 5 min. Reaction mixture without DNA template was used as a negative control and that with known DNA template was used as a positive control, which yielded PCR products of expected results. Reaction mixtures were as aforementioned, except that $2.5 \mu \mathrm{L}$ of product from the first step as template DNA and the second primers set were used.

\section{RFLP analysis}

The PCR product was then analyzed by RFLP. The PCR product from second step digested overnight at $37^{\circ} \mathrm{C}$ with $B s t U$ l restriction enzyme (Fermentas, Germany), according to the manufacturer's instructions. The results of enzymatic digestion were visualized in a $2 \%$ agarose gel by electrophoresis and ethidium bromide staining.

\section{Statistical analysis}

Analysis of p53 gene polymorphism in prostate cancer cases was performed using the SPSS version 17.0 computer software (SPSS, Chicago, IL). 95\% confidence intervals for the observed genotype frequencies were calculated. The Chi-squared test was used to establish whether the sample and control groups were in HardyWeinberg equilibrium, and whether the proportions of the three $p 53$ codon 72 genotypes differed between the cases and control groups.

Allele's frequency and their standard error were calculated as follows:

$N_{A}=2 \times N A A N A B \Rightarrow$

$$
F_{A}=\frac{2 N A A 2 N B l}{2 N}
$$




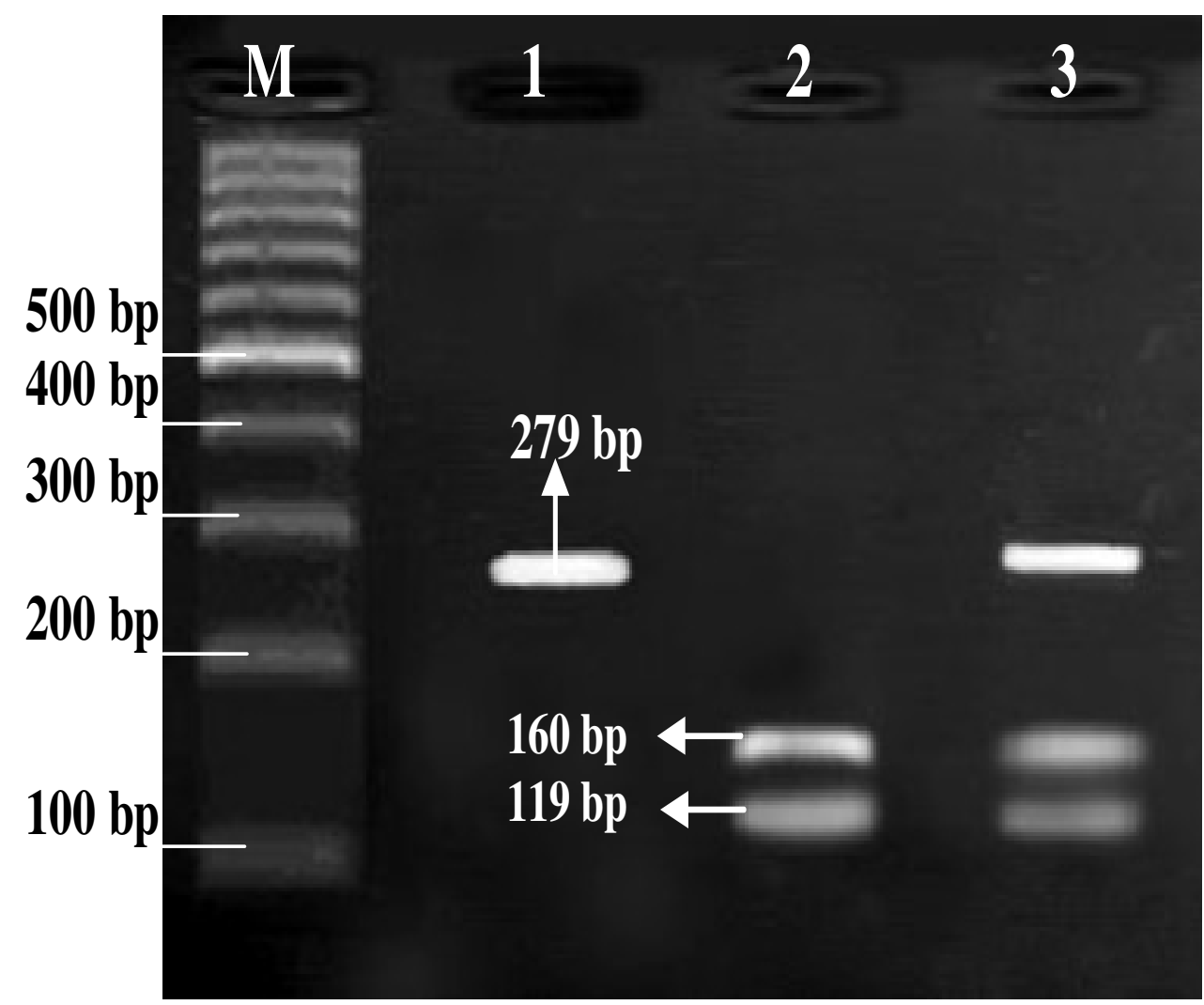

Figure 1. The PCR-RFLP analysss of $p 53$ codon 72 after digestion with BstUl enzyme. Lane M is $100 \mathrm{bp}$ DNA ladders (Fermentas, Germany), lane 1 is homozygote sample for Pro allele, lane 2 is $\mathrm{Arg} / \mathrm{Arg}$ homozygote and lane 3 is $\mathrm{Arg} /$ Pro heterozygote specimen.

Also standard error of mean allelic frequencies of p53 gene was calculated as:

$s . e=\sqrt{\frac{p q}{2 n}}$

To test deviation from Hardy-Weinberg equilibrium, the following Equations were used:

$$
x^{2}=\frac{\sum(0-e)^{2}}{e} \quad G^{2}=-2(\operatorname{LnLo}-\operatorname{LnL1})
$$

\section{RESULTS}

The results were the $279 \mathrm{bp}$ fragment of uncut PCR product representing homozygotes proline, two fragments of 160 and 119 bp representing homozygotes arginine, and three fragments 279, 160 and 119 bp representing heterozygotes (Arg/Pro) for codon 72. A representative Nested-PCR and RFLP pattern is depicted in Figure 1.

The frequencies of the Arg/Arg, Arg/Pro, and Pro/Pro genotypes in the control group were 27.03, 60 and $12.97 \%$ respectively. Among the 187 prostate cancer cases, 74 cases (39.57\%) were homozygous for the Arg 72 allele (Arg/Arg), 15 cases (8.02\%) were homozygous for the Pro 72 allele (Pro/Pro) and 98 cases (52.41\%) found in heterozygous (Arg/Pro). The distribution of the three different TP53 codon 72 genotypes (Arg/Arg, Arg/Pro, and Pro/Pro) in both groups (cases and controls) is presented in Table 1.

First, we compared the genotype frequencies between prostate cancer patients and normal controls, thus confirming the accumulation of $\mathrm{Arg} / \mathrm{Arg}$ genotype in these patients (39.57\% vs. $27.03 \%, \mathrm{P}>0.001)$.

Likewise, the distribution of the Pro allele variant between case and control groups was not statistically different $(P>0.05)$. In the current study, the $p$-value is less than 0.05 (5\%), so $\mathrm{Arg} / \mathrm{Arg}$ genotype in prostate cancer patients is statistically significant. Comparison of the allele frequencies revealed an increase in the Arg allele among prostate cancer patients compared to controls (Table 2).

\section{DISCUSSION}

The mutation of the $p 53$ gene is one of the most frequent genetic changes found in human cancers such as cervical cancer, breast cancer, colorectal and prostate cancer. In addition to mutations that arise during the 
Table 1. Distribution of p53 codon 72 polymorphism genotypes among prostate cancer cases and controls in Southwest Iran.

\begin{tabular}{lrrrrr}
\hline \multirow{2}{*}{ Genotype } & \multicolumn{2}{c}{ Cases (N = 187) } & \multicolumn{2}{r}{ Controls (N = 185) } & \multirow{2}{*}{ P-Value } \\
\cline { 2 - 5 } & $\mathbf{N}$ & $\%$ & $\mathbf{N}$ & $\%$ & \\
\hline Arg/Arg & 74 & 39.57 & 50 & 27.03 & $>0.001$ \\
Arg/Pro & 98 & 52.41 & 111 & 60 & $>0.05$ \\
Pro/Pro & 15 & 8.02 & 24 & 12.97 & $>0.001$ \\
\hline
\end{tabular}

Table 2. Allele frequencies of TP53 codon 72 among prostate cancer cases and controls in Southwest Iran.

\begin{tabular}{crrrrr}
\hline \multirow{2}{*}{ Allele } & \multicolumn{2}{c}{ Cases frequency } & \multicolumn{2}{c}{ Controls frequency } & \multirow{2}{*}{ P-Value } \\
\cline { 2 - 5 } & $\mathbf{N}$ & $\%$ & $\mathbf{N}$ & $\%$ & \\
\hline Arg & 123 & 65.77 & 106 & 57.03 & $>0.001$ \\
Pro & 64 & 34.23 & 79 & 42.97 & $>0.001$ \\
\hline
\end{tabular}

growth and development of individuals (sporadic mutations), there are forms of cancer associated with the inheritance of a damaged version of $p 53$ (Pezeshki et al., 2006; Pietsch et al., 2006). The p53 gene is known to exhibit distinct mutational patterns in various cancer types. The frequency of $p 53$ mutations in $p 53$ in prostate cancer is lower than in other carcinomas, such as esophageal carcinoma and oral squamous cell carcinoma, in which the frequency of p53-specific antibodies in patients' serum is high (Kubota et al., 2008). The proline/arginine substitution at codon 72 represents a common amino acid polymorphism in the p53 gene, the functional significance of which is unknown (Onrat et al., 2009). This may be due to the production of a mutant p53 protein that is not capable of inducing apoptosis in response to toxic environmental stimuli (Lung et al., 2004).

Few studies have been conducted on the risk factors for prostate cancer in the Iranian context. The incidence of prostate cancer in Iran is very low as compared to the Western countries (Pourmand et al., 2007). This can partly be explained by lack of nationwide screening program, younger age structure and quality of cancer registration system in Iran. The findings of this study showed that prostate cancer is one of the most common cancers in Southwest Iran among males (Hosseini et al., 2009; Marjani and Kabir, 2008). In the present study, we also evaluated the role of the TP53 Arg72Pro polymorphism in the prostate patients. The evaluation showed a statistically significant difference in overall survival among the individuals with different genotypes. The frequencies of $p 53$ codon 72 genotype in prostate cancer cases revealed 74 cases $(39.57 \%)$ arginine homozygotes $(A r g / A r g), 15$ cases $(8.02 \%)$ proline homozygotes (Pro/Pro) and 98 cases (52.41\%) arginine/proline heterozygotes (Arg/Pro). Frequencies of Arg/Arg, Arg/Pro and Pro/Pro in p53 among controls were $50(27.03 \%), 111(60 \%)$ and $24(12.97 \%)$, respectively.
In the current study, the frequency of $p 53$ codon 72 genotypes among the controls and patients closely conformed to Hardy-Weinberg equilibrium and we found significant differences in the genotype or allele frequencies between the patients and the control groups. Moreover, the results show increases in the Arg/Arg genotype and a decrease in Pro/Pro genotype among patients and an increase in the Arg allele. Many studies were performed about p53 codon 72 polymorphisms and its correlation to cancer diseases in patients in Iran and other places. Hosseini et al. (2009) showed that several recognized risk factors for prostate cancer contributes evidence to the discussions of other hypothesized risk factors, and points to potentially new factors in Iran. In Golestan, north province of Iran harbor, a rather incidence for prostate cancer (in age 80 to 84), comparable to the lower incidence rate reported in the world was reported (Marjani and Kabir, 2008).

In prostate cancer, studies of p53 codon 72 polymorphism have shown different results in different populations. The findings of Huang et al. (2004) showed that $\mathrm{Arg} / \mathrm{Arg}$ genotype was associated with BPH risk in those with large prostate volumes (Huang et al., 2004). A number of studies have failed to demonstrate the association between the $p 53$ codon 72 polymorphism prostate cancers. For example, Henner et al. (2001) showed the Pro/Pro genotype was associated with a markedly lower risk of prostate cancer and men with the p53 codon 72 Pro/Pro genotypes appear to be at reduced risk of prostate cancer. Suzuki et al. (2003) showed that Pro/Pro genotype of $p 53$ codon 72 played a role in prostate cancer susceptibility in a Japanese population. However, the Pro allele did not appear to worsen such clinical parameters as clinical stage or pathological grade. The results of the study of Lima-Ramos et al. (2008) for role of TP53 Arg72Pro polymorphism in a large series of Portuguese glioma tumors showed no association with glioma susceptibility or overall survival, 
except for patients submitted to adjuvant therapy. The findings of Cao et al. (2009) also indicated that p53 Pro72 variant is associated with an increased risk for colorectal cancer in the Korean population. In addition, the p53 codon 72 polymorphism associations with bladder cancer and that genotypic distribution of this polymorphism were showed by $\mathrm{Li}$ et al. (2010) in China. In agreement with prior studies on breast, colorectal and prostate cancer in Iran, we found significant differences in the genotype or allele frequencies between the patients and the control groups (Mojtahedi et al., 2010). More also, the allele and genotype frequencies of the $p 53$ codon $72 \mathrm{Arg} / \mathrm{Arg}$ polymorphism in stomach, colorectal adenocarcinoma, breast and prostate cancer patients compared to the healthy individuals from the population of Southern Iran showed significant differences in the genotype or allele frequencies between the patients and the control groups (Khadang et al., 2007).

In conclusion, the findings of present study suggested that Arg/Arg genotype could be a risk factor for the development of prostate enlargement and cancer, and p53Arg72 protein may be correlated with possible increased risk of this kind of cancers in southwest Iran.

\section{ACKNOWLEDEGEMENTS}

The authors would like to thank all the staff of the Biotechnology Research Center of Islamic Azad University of Shahrekord Branch in southwest Iran for their sincere support.

\section{REFERENCES}

Cao Z, Song JH, Park YK, Maeng EJ, Nam SW, Lee JY, Park WS (2009). The p53 codon 72 polymorphism and susceptibility to colorectal cancer in Korean patients. Neoplasma. 56 (2): 114-118.

Guan YS, He Q, La Z (2006). Roles of p53 in Carcinogenesis, Diagnosis and Treatment of Hepatocellular Carcinoma. J. Canc. Mol. 2(5): 191-197.

Henner WD, Evans AJ, Hough KM, Harris EL, Lowe BA, Beer TM (2001). Association of codon 72 polymorphism of $p 53$ with lower prostate cancer risk. Prostate. 49(4): 263-266.

Hosseini M, Seyed Alinaghi SA, Mahmoudi M, McFarland W (2009). A case-control study of risk factors for prostate cancer in Iran. Acta Medica. Iranica. 48(1): 61-66.

Huang SP, Wu WJ, Chang WSW, Wu MT, Chen YY, Chen YJ, Yu CC, Wu TT, Lee YH, Huang JK, Huang CH (2004). p53 codon 72 and p21 codon 31 polymorphisms in prostate cancer. Cancer Epidemiol. Biomark. Prev. 13(12): 2217-2224.

Khadang B, Fattahi MJ, Talei A, Dehaghani AS, Ghaderi A (2007). Polymorphism of TP53 codon 72 showed no association with breast cancer in Iranian women. Canc. Genet. Cytogenet. 173: 38-42.
Kubota Y, Onmura Y, Ohji H, Kunii T, Shibasaki T, Nakada T, Tomita Y (2008). p53 antibodies in the serum of patients with prostate cancer. Int. Urol. Nephrol. 40: 79-84.

Li DB, Wei X, Jiang LH, Wang Y, Xu F (2010). Meta-analysis of epidemiological studies of association of $P 53$ codon 72 polymorphism with bladder cancer. Genet. Mol. Res. 9(3): 1599-1605.

Lima-Ramos V, Pacheco-Figueiredo L, Costaa S, Pardal F, Silvab A Amorim J, Lopes JM, Reis RM (2008). TP53 codon 72 polymorphism in susceptibility, overall survival, and adjuvant therapy response of gliomas. Canc. Genet. Cytogenet. 180: 14-19.

Lung FW, Lee TM, Shu BC, Chang FH (2004). p53 codon 72 polymorphism and susceptibility malignancy of colorectal cancer in Taiwan. J. Cancer Res. Clin. Oncol. 130: 728-732.

Marjani A, Kabir MJ (2008). Prostate cancer incidence in Golestan province, Iran (2004). Am. J. Biochem. Biotechnol. 4(1): 57-60.

Mojtahedi Z, Haghshenas MR, Hosseini SV, Fattahi MJ, Ghaderi A (2010). p53 codon 72 polymorphism in stomach and colorectal adenocarcinomas in Iranian patients. Ind. J. Cancer. 47(1): 31-34.

Onrat ST, Ellidokuz E, Kupelioglu A, Durhan E (2009). Frequency of TP53 codon72 polymorphism in cases with colon cancer. Turk. J. Cancer, 39(1): 5-10.

Pezeshki A, Sari-Aslani F, Ghaderi A, Doroudchi M (2006). p53 Codon 72 Polymorphism in Basal Cell Carcinoma of the Skin. Pathol. Oncol. Res. 12(1): 29-33.

Pietsch EC, Humbey O, Murphy ME (2006). Polymorphisms in the p53 pathway. Oncogene.25: 1602-1611.

Pourmand G, Salem S, Mehrsai A, Lotfi M, Amirzargar MA, Mazdak H (2007). The risk factors of prostate cancer: a multicentric case-control study in Iran. Asian Pac. J. Cancer Prev. 8(3): 422-428.

Quinones LA, Irarrázabal CE, Rojas CR, Orellana CE, Acevedo C, Huidobro C, Varela NE, Caceres DD (2006). Joint effect among p53, CYP1A1, GSTM1 polymorphism combinations and smoking on prostate cancer risk: an exploratory genotype-environment interaction study. Asian J. Androl. 8(3): 349-355.

Sadjadi A, Nooraie M, Ghorbani A, Alimohammadian M, Zahedi MJ, Darvish-Moghadam S, Fakheri H, Babai M, Semnani S, MansourGhanaei F, Mohagheghi MA (2007). The incidence of prostate cancer in Iran: results of a population-based cancer registry. Arch Iranian Med. 10(4): 481-485.

Suzuki K, Matsui H, Ohtake N, Nakata S, Takei T, Nakazato H, Okugi $\mathrm{H}$, Koike H, Ono, Ito YK, Kurokawa K, Yamanaka H (2003). A p53 Codon 72 polymorphism associated with prostate cancer development and progression in Japanese. J. Biomed. Sci. 10(4): 430-435.

Vazquez A, Grochola LF, Bond EE, Levine AJ, Taubert H, Müller TH, Würl P, Bond GL (2010). Chemosensitivity profiles identify polymorphisms in the p53 network genes 14-3-3т and CD44 that affect sarcoma incidence and survival. Cancer Res. 70(1): 172-180.

Zhu Y, Wang J, He Q, Zhang JQ (2010). Association of p53 codon 72 polymorphism with prostate cancer: a meta-analysis. Mol. Biol. Rep. 27(2): 540-546. 